\title{
Pandemia na necroeconomia neoliberal
}

\author{
Pandemic in neoliberal necroeconomics
}

\author{
Cristina Scheibe Wolff ${ }^{1}$ \\ 0000-0002-7315-1112 \\ Luzinete Simões Minella ${ }^{1}$ \\ 0000-0001-7953-7385 \\ Mara Coelho de Souza Lago' ${ }^{1}$ \\ 0000-0001-5111-8699 \\ Tânia Regina Oliveira Ramos' (iD) 0000-0002-2477-0419 \\ 'Universidade Federal de Santa Catarina, Florianópolis, SC, Brasil. 88040-900
}

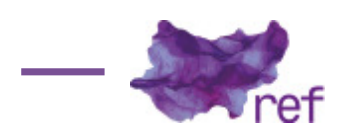

Estamos vivendo, desde meados de março de 2020, no Brasil, uma situação excepcional, gerada pela pandemia do coronavírus, cientificamente codificada em suas siglas como doença, classificada como substantivo feminino, a Covid-19. A própria definição de pandemia implica uma questão mundial, que atinge de alguma maneira a todas e todos: Oriente e Ocidente; Norte e Sul; pobres e ricos; mulheres e homens, cis e trans, homossexuais e heterossexuais; pessoas indígenas, negras, brancas, orientais. Entretanto, como Boaventura de Souza Santos (2020) e tantas autoras e autores têm argumentado, essa ideia de uma "igualdade" frente ao vírus é uma ficção, já que a doença não atinge a todas da mesma forma e com a mesma intensidade. Se algumas/ uns de nós podem estar em isolamento nos espaços domésticos, trabalhando com seus computadores e internet, outras pessoas não têm essa possibilidade. Segundo este autor, a pandemia e o confinamento como prevenção para a mesma promovem e revelam as cisões perversas das sociedades, que tornam alguns grupos sociais mais suscetíveis em razão de suas condições socioeconômicas e da falta de políticas públicas adequadas, visibilizando os que estão "ao sul da quarentena": mulheres, trabalhadoras e trabalhadores precários ou informais, moradoras e moradores de rua, de periferias pobres e de favelas, as/os internadas/os em campos de refugiados e prisões, idosas/os, deficientes físicos (SANTOS, 2020, p. 15-21). Esses "grupos vulneráveis" formam a maioria das pessoas no planeta, aquela maioria que não está protegida pela redoma dos planos de saúde, das casas com internet rápida, dos empregos em instituições e empresas que permitem home office e continuam pagando salários, das pessoas que podem comprar alimentos e refeições por delivery.

Sobre as mulheres recai uma carga pesadíssima nesse contexto de pandemia e isolamento social pois, apesar de todas as lutas feministas, são elas que assumem a responsabilidade e a maior parte das tarefas domésticas e de cuidado. Somando-se a isso, cerca de $70 \%$ das profissionais de saúde são também mulheres e, conforme Hildete Pereira de Melo (2020), no Brasil como em outros países, essa situação ainda se agrava pela condição econômica das mulheres, que continuam ganhando em média $25 \%$ a menos que os homens. Questão que se amplia significativamente no caso das mulheres negras, que formam grande parte das trabalhadoras informais, em condições precárias de trabalho, sem acesso a registros, e que na pandemia têm perdido seus empregos. Com todas as pessoas da família constantemente em casa, com as escolas e creches fechadas, com os serviços de saúde limitados, são geralmente as mulheres que se encarregam do preparo da comida, da limpeza, da higienização de tudo que é comprado, da roupa, dos cuidados com as crianças e adolescentes (incluídas as atividades escolares), com as pessoas doentes e idosas, para além de seu trabalho remunerado quando este se mantém.

A crise no Brasil se agrava ainda mais pela maneira disfuncional como o governo atual tem lidado com ela, e também por medidas adotadas anteriormente que retiraram verbas e todo tipo de apoio à pesquisa científica, ao serviço público, desconstruindo políticas públicas de apoio às populações mais pobres. O aumento da violência contra as mulheres, assinalado pela diretora- 
executiva da ONU Mulheres, Phumzile Mlambo-Ngcuka (2020), por exemplo, não é simplesmente o resultado do isolamento social, pois já vem aumentando nos últimos anos, mas também deriva da apologia da "família estruturada" (leia-se patriarcal), do uso de armas, da diminuição de recursos e pessoal nas instituições que deveriam assistir as pessoas em situação de violência. O aumento da violência em nossas sociedades tem resultado em expressiva produção de artigos submetidos aos periódicos acadêmicos sobre o tema nos últimos tempos. Este número da REF vem corroborar tal constatação.

As distintas formas de violência contra as mulheres que têm persistido e se ampliado no Brasil, conforme atestam dados amplamente divulgados na última edição do Atlas da Violência, organizado pelo Instituto de Pesquisa Econômica Aplicada em parceria com o Fórum Brasileiro de Segurança Pública (2019), revelam uma das faces mais sombrias das desigualdades de gênero em suas interseções com as discriminações étnico-raciais, de classe social e gerações. Entre outros aspectos, a referida publicação ressalta que "houve um crescimento dos homicídios femininos no Brasil em 2017, com cerca de 13 assassinatos por dia. Ao todo, 4.936 mulheres foram mortas, o maior número registrado desde 2007" (2019, p. 35). Entre elas, as mulheres negras foram as mais atingidas, os parceiros ou ex-parceiros foram em grande maioria os autores, tendo boa parte dos assassinatos acontecido no ambiente doméstico.

O resultado de uma pesquisa recente sobre violência contra as mulheres no contexto da pandemia da Covid-19, realizada pelo mesmo Fórum a partir dos dados obtidos nas Secretarias Estaduais de Segurança Pública e/ou Defesa Social e nos Tribunais de Justiça de seis estados brasileiros sugere que tem havido subnotificação dos casos em razão, inclusive, das medidas de isolamento social. Na segunda parte desse estudo, realizada em parceria com a empresa Decode Pulse, especialista em levantamentos de dados em redes sociais, entre outros aspectos preocupantes, ressalta-se que houve um aumento considerável de relatos de brigas de casais e de violência doméstica no Twitter (2020).

Em meio a essa crise se apresentam muitos dilemas, que implicam decisões pessoais, mas principalmente políticas, marcadas por desvarios como os que pedem a volta da ditadura, ou a intervenção militar e ameaças ao estado "democrático" pelo próprio chefe de Estado. A cada dia recebemos uma ou mais notícias que afetam as universidades e todas as instituições acadêmicas: escolha do reitor pelo chefe do executivo nacional, corte das bolsas e auxílios para as humanidades e ciências sociais no CNPq, cortes de bolsas de pós-graduação pela CAPES e CNPq, terraplanismo, criacionismo, guerra aos estudos de gênero. O panorama chega a ser surreal. Ao mesmo tempo, vemos as vizinhanças e favelas se organizando para enfrentar a crise, campanhas de solidariedade, e uma crescente rejeição ao governo. Há muito que fazer, e os feminismos estão na pauta da sociedade, das lives a cursos on-line. A publicação de periódicos feministas e de gênero se constitui como um ato de resistência, nas difíceis condições pelas quais passam os diferentes países, numa nova cartografia e, de forma muito grave, no Brasil, onde o governo tem assumido, como já apontamos, posições inaceitáveis frente à pandemia, não só aos nossos olhos, mas aos olhos do mundo inteiro.

A Seção Temática deste número da REF, desde o título Feminismos, afecto y política, que trata dos sentimentos, afetos, emoções nas configurações das subjetividades, traz bem marcadas para todas/os nós as emoções que temos experimentado individualmente ou compartilhado nas escritas e conversas virtuais, com as sucessões de notícias diárias que nos tomam de assalto nas quarentenas diferenciadas que temos vivido, algumas/uns na solidão necessária, outras/os em isolamentos familiares, muitas/os em situações de graves riscos sem terem como se isolar: as pessoas que trabalham em serviços essenciais, as que precisam continuar em seus trabalhos precários, multiplicadas pelo desmanche das leis trabalhistas e pelo ataque às políticas públicas perpetrado pela necropolítica (Achille MBEMBE, 2018) praticada no país, e aquelas a quem foram negadas desde sempre quaisquer oportunidades de vida ou moradia dignas.

Nos impasses entre economia e pandemia que nos têm sido postos pelo governo federal e as chamadas elites - empresariais, rentistas - deste país da desigualdade, que contrapõe a escolha entre salvar os CNPJs ou os CPFs (nossos registros institucionais de pessoas jurídicas, o primeiro, ou pessoas físicas, o segundo), estamos tomadas/os por emoções à flor da pele. Pela revolta, o pânico, sentimentos de profunda tristeza, de impotência, de perda. As mortes de brasileiras e brasileiros e as terríveis cenas de enterros num continuum de valas abertas por trabalhadores braçais e escavadeiras, de caixões enfileirados em cemitérios superlotados de diferentes regiões do país, intensificam o luto pela perda de pessoas próximas, pelo número expressivo de mortes de profissionais da saúde, pela perda de pessoas que conhecíamos pelas artes que produziam - mortes que simbolizam todas as mortes que se acumulam assustadoramente na luta contra a doença.

Muito das narrativas que buscamos construir nessa história do tempo presente em função das atitudes do presidente do país e dos cúmplices que o apoiam e o sustentam revela que estamos, sim, num estado de exceção. Aquele estado teorizado por autores como Frantz Fanon (1968), Giorgio Agamben (2004), Mbembe (2018), que extrapola a guerra, o extermínio colonial, e se estende e permanece, perpetuando o genocídio dos corpos racializados, os corpos que, sim, 
importam: velhos, pobres, sobretudo os corpos indígenas, quilombolas, negros, vítimas contumazes do capitalismo e da necroeconomia neoliberal, que busca se manter no país que elegeu em 2018 uma extrema direita fundamentalista, com as consequências vividas agora.

O primeiro texto que compõe este número 2 do volume 28 da Revista Estudos Feministas é a tradução feita por Luciana Valio do artigo de Silvia Federici, In Struggle to Change the World: Women, Reproduction, and Resistance in Latin America, publicado em The documenta Reader Catalogue.documenta e Museum Fridericianum Kassel: Prestel Verlag, em 2017. É um texto de grande interesse para o campo feminista na América Latina, que inicia com a referência ao impeachment de Dilma Roussef no Brasil, indicador, para Federici, junto a outros processos eleitorais ocorridos, como o de Macri na Argentina, do fim de governos progressistas no Continente. A autora ressalta que estes governos que começavam então a ser substituídos haviam instituído medidas para a diminuição das desigualdades em seus países, não tendo, no entanto, enfrentado as estruturas do liberalismo econômico que sustentam a concentração de rendas no capitalismo. $O$ artigo de Federici passa a analisar diferentes experiências protagonizadas por mulheres latinoamericanas, indígenas, camponesas, citadinas, em movimentos de resistência que recuperam/ instituem práticas comunitárias, representando lutas feministas do que teoriza como as comuns.

Este texto antecipa questões muito atuais neste ano 2020 da pandemia: a evidência, para além dos campos das chamadas esquerdas políticas dos diferentes países, da falência do Estado Mínimo do capitalismo local e global, com sua incapacidade para fazer frente a um problema de saúde como o que estamos vivenciando todos e que está resultando, além das inaceitáveis e crescentes perdas de vidas, no colapso das economias globais pela suspensão das atividades produtivas, em função do isolamento necessário para fazer frente ao potencial de contágio do coronavírus. As perguntas que se têm colocado: ocorrerão mudanças estruturais com a superação do capitalismo ultraliberal rentista da globalização, ou haverá um agravamento da perversa concentração de renda em curso nos países ocidentais? Aprenderemos outras formas de relações e comportamentos, como nos ensinam muitas nações indígenas e outros povos da América Latina e alhures, a exemplo das mulheres estudadas por Federici com suas práticas coletivas, comunitárias de resistência, ou continuaremos nesta escalada do individualismo que, conforme afirmava Louis Dumont (1985) no século passado, é a ideologia diferenciadora que marca as sociedades ocidentais (agora aprofundada pelos avanços das tecnologias digitais)? As respostas de analistas políticos têm se dado num continuum de pessimismos a otimismos esperançosos nas mudanças e aprendizagens...

Nesse contexto marcado pelos impactos da pandemia, a REF cumpre mais uma vez seu papel na construção das urgências e do pensamento crítico e divulga nesse número o artigo de Juan Pablo Bohoslavsky, em coautoria com Mariana Rulli, a respeito de um aspecto que tem sido pouco contemplado pela literatura sobre o tema: o caráter androcêntrico das políticas das instituições financeiras internacionais frente aos efeitos devastadores da Covid-19 no cotidiano das mulheres, principalmente as latino-americanas, analisado a partir da perspectiva dos direitos humanos e da economia feminista. Esta face da violência analisada por autor/a vem corroborar os dados trazidos pelo Atlas da Violência, já citado.

Dada a gravidade da situação atual, as violências contra as mulheres voltam a ser contempladas nesse número, em quatro artigos: o primeiro deles, elaborado por Tássia Rabelo de Pinho, aborda o silêncio do Conselho de Ética da Câmara dos Deputados diante da violência política de gênero. A autora realizou um levantamento sobre a participação das mulheres nesse Conselho, analisando os encaminhamentos dados às denúncias de violência política sofridas pelas parlamentares. ' $O$ artigo de Juliana de Oliveira Horst e Katie Cáceres Arguello reflete sobre a exclusão dos relatos das mulheres na produção dos saberes, argumentando em favor da articulação entre conceitos feministas, opressões de gênero e criminologia, de modo a favorecer uma compreensão mais fundamentada das nuances da criminalidade feminina.

Os três artigos seguintes exploram outros aspectos igualmente relevantes: Paloma Afonso Martins e Christiane Carrijo refletem sobre as relações entre violência doméstica e racismo a partir dos relatos de mulheres negras, contribuindo para questionar o mito da democracia racial; Alice de Barros Gabriel e Breno Ricardo Guimarães propõem uma discussão sobre a dimensão epistêmica da categoria violência obstétrica - a partir do conceito de injustiça epistêmica - e analisam relatos específicos desse tipo de violência com vistas a contribuir para seu enfrentamento; os efeitos do projeto "Lei Maria da Penha vai às Escolas" são analisados por Kristine Albuquerque, ressaltando seu compromisso com a prevenção e com a formação de uma consciência crítica sobre as relações de gênero.

A linguagem tem sido uma constante presença analítica, teórica e crítica entre os artigos publicados, seja como dados estruturantes das narrativas ideológicas, seja como evidências das singularidades das autorias que se empenham no pensar a arte e a literatura. Assim se evidenciam

' O artigo recebeu o prêmio Marielle Franco, da Seção de Estudos de Gênero e Feministas da Latin American Studies Association (LASA), em 2019. 
as leituras aqui dedicadas a ouvir a voz de Lidia Amadio, na entrevista feita por Barbara Arisi com esta dirigente da Orquestra Filarmônica de Montevidéu, neste lugar tão raro na história das mulheres. Os Corpos de mulheres descolonizadas são refletidos nas obras da escritora, teatróloga e cineasta argelina Assia Djebar, em artigo de Dolores Serrano-Niza. A escrita engajada de Carolina Maria de Jesus nos traz seu potencial de denúncia e de anúncio, sua contribuição para o feminismo interseccional e, ainda, a relação indissociável entre feminismo e decolonialidade. Ancorado na biografia de Nísia Floresta, o artigo seguinte reflete sobre a procedência do primeiro livro da escritora e seu papel no nascente ideário feminista brasileiro. A representação da mulher durante o período medieval e a presença desta concepção imaginária como construtora de sentidos ecoa na narrativa fílmica The Magdalene Sisters, de Peter Mullan (2002). Outro texto nos mostra que os debates no campo do Jornalismo sobre/a partir das temáticas de gênero ainda são incipientes, apesar da urgência da construção de discussões que repensem as práticas da profissão, as relações entre os profissionais e o ensino. Em artigo que analisa as percepções de mulheres esportistas sobre as programações esportivas nos meios de comunicação, os resultados da pesquisa atestam que as media visibilizam as atividades esportivas masculinas, numa usurpação do espaço mediático do esporte feminino.

Discursividades de identidades, sexualidades, feminismos são analisadas em postagens que refletem sobre os modos como as redes sociais na Internet contribuem para a ressignificação das práticas de linguagem, caracterizando-se como espaço-tempo significativo de embate de vozes, bem como ambiente de posicionamento performativo. Os comentários alheios sobre corporalidades são analisados em artigo que reflete sobre os significados atribuídos por mulheres que se autodeclaram gordas, às suas experiências corporais cotidianas. Pesquisa realizada com mulheres militantes de movimentos sociais aborda as relações entre militâncias e subjetividades, trazendo discussões e perspectivas que extrapolam as estatísticas sobre aborto. Outro tema relevante, a viuvez das mulheres, é discutido em artigo em que as autoras exploram os enfoques presentes na literatura sobre o tema nas ciências sociais, identificando "três eixos temáticos": viuvez como construção social, como vulnerabilidade ou como possibilidade de transformação com alternativas para a ressignificação do conceito e, consequentemente, da viuvez vivida por mulheres. A literatura e a arte instauram assim um universo imaginário e se mostram em cada artigo como uma verdade histórico-social capaz de nos convencer que criticar é ler, potencialmente ler.

Os artigos seguintes trazem resultados de pesquisas realizadas em diferentes países da América Latina referidos a vários temas e evidenciando aspectos geracionais e vulnerabilidades. Um dos artigos discute o caso da condenação de Talia Lluy Gonzalez no Equador, em decisão que foi derrubada pela Corte Interamericana de Direitos Humanos sobre contágio pelo vírus HIV, com a condenação do Estado réu e a garantia dos direitos da requerente. Pesquisa com mulheres que optaram por cumprir pena com os companheiros encarcerados no Rio de Janeiro revela que, apesar de assumirem papéis femininos tradicionais de cuidados, exercem também funções emancipadoras. Etnografia realizada com mulheres jovens moradoras de rua em Bogotá sobre construção de corpos femininos neste espaço de leitura violenta do feminino utiliza novos instrumentos metodológicos no interesse da politização do cotidiano destes corpos. A investigação sobre autonomia feminina nas negociações sexuais, realizada com mulheres adolescentes que vivem em relações heterossexuais no Chile, revelou a permanência de imaginário naturalizador de práticas de controle masculino, obstaculizando as negociações em sexualidade pelas adolescentes estudadas.

O ensaio publicado neste número faz dialogarem o texto de Michel Foucault sobre a miséria do amor moderno fundada, segundo o filósofo, na ressignificação do remorso cristão feita pela psicanálise, com texto de Judith Butler que toma a questão freudiana da melancolia para teorizar sobre a concepção de melancolia desviante do amor da filósofa, ligada por ela à subversão da heterossexualidade.

Os artigos que compõem a Seção Temática já referida contribuem para evidenciar a concepção de suas organizadoras Mariela Solana e Nayla Vacarezza de que o "giro afectivo" trazido pelas epistemologias feministas fundamentou o aprofundamento das análises sobre as dimensões emocionais nas ciências sociais. As oito resenhas que finalizam esse número dão continuidade à tradição da Revista, pois divulgam obras recentes sobre temas instigantes, por exemplo, feminismos nos países da América Latina, relações familiares, sexualidade, representações sobre gênero.

Só vivemos de desesperança? No contexto brasileiro ela prevalece. Mas lançamos também nosso olhar para o mundo que vem se recuperando lentamente de seus lockdown e do isolamento social. As pesquisas médicas e o empenho no combate e na compreensão do vírus têm sido uma busca constante em diversos países, sem adesão à fórmula mágica da cloroquina propalada no Brasil. Na China são quatro vacinas sendo testadas em seres humanos. Nos Estados Unidos, os laboratórios que estão envolvidos na produção de vacinas contam com listas de voluntários que se dispuseram a participar dos testes. Os países europeus ocidentais têm investido altas somas 
nessa corrida. Na Rússia não tem sido diferente, nem no Japão e em outros países asiáticos. 0 êxito nessas missões científicas significará prestígio para os grupos envolvidos. As equipes multidisciplinares têm trabalhado em rede, disponibilizando aquilo que se descobre num grupo situado num determinado país, pela publicação imediata nos demais, havendo inclusive um acordo internacional sobre divulgação praticamente em tempo real, ou seja, em preprint, dos resultados de pesquisas sobre vacinas e medicamentos. Sabemos que crises como as da saúde não são sinônimos de paralisia quando se trata do avanço do conhecimento. Contextos de crises obrigaram a avanços significativos no âmbito do conhecimento da fisiologia humana, da biomedicina à farmacologia: analgésicos, anestésicos, penicilina, antibióticos, avanços nas vacinas, novas técnicas cirúrgicas, novos tratamentos, novos aparelhos para diagnósticos. São muitos os grupos de pesquisa dedicados aos estudos do vírus causador desta pandemia. No Brasil, apesar da falta de incentivo do poder público, são cerca de 800 pesquisas sobre vários aspectos do vírus, sem esquecer que duas cientistas brasileiras coordenaram a equipe que mapeou o novo coronavírus: Ester Sabino (JORNAL DA CIÊNCIA, 2020a), especialista em epidemias, com 30 anos de carreira, e Jaqueline Goes de Jesus (JORNAL DA CIÊNCIA, 2020b), uma mulher nordestina e negra, representante das novas gerações de pesquisadoras na área da biomedicina.

Escrevemos este editorial em torno do septuagésimo dia de nossos isolamentos entremeados de trocas de ministros, de falta de uma política de saúde pública, de angústias, de descobertas, de trincheiras de luta e resistência e da certeza de que não estamos sós. O cotidiano é de números, de vidas e de mortes. No Brasil há uma dupla luta contra o mal e a maldade: não só as dificuldades da ciência em função da COVID-19, mas a atitude do poder instituído pelo voto irresponsável, e pelo desrespeito, pelo deboche, pela negação, pelas ameaças, pelas escatologias e obscenidades nas reuniões ministeriais, pelo desrespeito especialmente em relação à velhice e aos grupos de risco. Estamos aqui abraçando, como já mencionamos, as $70 \%$ de mulheres na linha de frente na luta contra a pandemia, médicas, enfermeiras, assistentes sociais. Em nós e nelas a atenção, o cuidado e a cura. Por essa razão nosso editorial quer também fazer uma referência às crianças e aos adolescentes pela forma que estão construindo uma respeitosa compreensão do vírus. Será através delas que o futuro elaborará significativas narrativas, nas quais a memória será uma inegável oportunidade poética na elaboração de suas lembranças compartilhadas e de como as paredes sólidas de suas escolas se fragilizaram diante do vírus que antes só existia como conteúdo abstrato nas aulas de Ciências e Biologia. Estudantes que se encontram em casa e, supomos, muitos em condições protegidas junto às famílias. Mas a notícia da morte, em casa, de João Pedro Matos Pinto, de 14 anos, baleado em uma operação policial da "guerra" ao tráfico no Complexo do Salgueiro, Rio de Janeiro, nos enche de revolta e dolorida tristeza com o país do genocídio de corpos negros, jovens. Mais uma vez e sempre, mortes impunes!

Para terminar este editorial histórico, trazemos a poesia dos versos de Arnaldo Antunes e Péricles Cavalcanti, cantados por Adriana Calcanhotto, que ilustram tão bem e profeticamente a verticalização do preconceito e da ideia da existência na sua frágil relação com o tempo:

Antes de mim vieram os velhos / os jovens vieram depois de mim / no meio do caminho dessa vida / vinda antes de nós / e estamos todos a sós / no meio do caminho dessa vida / e estamos todos no meio / quem chegou e quem faz tempo que veio / ninguém no início ou no fim. / Antes de mim / vieram os velhos / os jovens vieram depois de mim. / E estamos todos aí.

Em meio às estatísticas das mortes, a de João Pedro simboliza as muitas outras vidas daqueles/ as que não estão mais aqui... Apegamo-nos na resistência. Difícil manter a esperança!

\section{Referências}

AGAMBEN, Giorgio. Estado de exceção. São Paulo: Boitempo, 2004.

CALCANHOTtO, Adriana. "Velhos e jovens". Senhas. Composição: Arnaldo Antunes; Péricles Cavalcanti. Columbia Records, 2002.

DUMONT, Louis. O Individualismo: uma perspectiva antropológica da Ideologia Moderna. Rio de Janeiro: Rocco, 1985.

FANON, Frantz. Os Condenados da Terra. Rio de Janeiro: Civilização Brasileira, 1968.

FEDERICI, Silvia. The documenta Reader Catalogue.documenta e Museum FridericianumgGmbH, Kassel: Prestel Verlag, 2017. p. 603-630.

FÓRUM BRASILEIRO DE SEGURANÇA PÚBLICA. Violência Doméstica durante a pandemia de Covid19. Nota Técnica, 16 de abril de 2020.

INSTITUTO DE PESQUISA ECONÔMICA APLICADA; FÓRUM BRASILEIRO DE SEGURANÇA PÚBLICA (Orgs.). Atlas da Violência, 2019. Brasília; Rio de Janeiro; São Paulo, 2019. 
JORNAL DA CIÊNCIA. Cientista tem que começar a falar com o público, diz pesquisadora, 10/03/ 2020a. Disponível em http://www.jornaldaciencia.org.br/edicoes/?url=http://jcnoticias.jornaldaciencia. org.br/7-cientista-tem-que-comecar-a-falar-com-o-publico-diz-pesquisadora/. Acesso em 20/03/2020.

JORNAL DA CIÊNCIA. Conheça a cientista, negra e nordestina, que coordena a luta contra o Covid-19 no Brasil, 21/05/2020b. Disponível em http://www.jornaldaciencia.org.br/edicoes/?url=http:/ /jcnoticias.jornaldaciencia.org.br/19-conheca-a-cientista-negra-e-nordestina-que-coordena-aluta-contra-o-covid-19-no-brasil/. Acesso em 22/05/2020.

MBEMBE, Achille. Necropolítica: biopoder, soberania, estado de exceção, política da morte. São Paulo: N-1 Edições, 2018.

MELO, Hildete Pereira de. "A vida das mulheres em tempos de pandemia". Fundação Friedrich Ebert, 13/04/2020. Disponível em https://www.fes-brasil.org/detalhe/a-vida-das-mulheres-em-temposde-pandemia/. Acesso em 11/05/2020.

MLAMBO-NGCUKA, Phumzile. "Violência contra mulheres e meninas é pandemia das sombras". Nações Unidas Brasil, 08/04/2020. Disponível em https://nacoesunidas.org/artigo-violencia-contramulheres-e-meninas-e-pandemia-das-sombras/. Acesso em 11/05/2020.

SANTOS, Boaventura de Souza. A cruel pedagogia do vírus. Coimbra: Almedina, 2020. Disponível em https://www.cpalsocial.org/documentos/927.pdf. Acesso em 1 1/05/2020.

Cristina Scheibe Wolff (cristiwolff@gmail.com) é doutora em História Social pela Universidade de São Paulo (1998). Possui Graduação em História pela Universidade Federal de Santa Catarina (1988), Mestrado em História pela Pontifícia Universidade Católica de São Paulo (1991). Em 2004/ 2005 realizou Pós-Doutorado na Université Rennes 2, na França, e entre 2010 e 201 1, no Latin American Studies Center da University of Maryland, em College Park, Estados Unidos da América. Ocupou a Cátedra Fulbright de Estudos Brasileiros na University of Massachusetts em Amherst (set.-dez. 2017) e foi pesquisadora convidada no Laboratoire Arenes - Université Rennes 2 (jan.-jul. 2018). Atualmente é Professora Titular do Departamento de História da Universidade Federal de Santa Catarina. É integrante do Laboratório de Estudos de Gênero e História (LEGH) e do Instituto de Estudos de Gênero da UFSC e uma das coordenadoras editoriais da Revista Estudos Feministas (2006-2009 e 2011atual). Foi coordenadora do Programa de Pós-Graduação em História da Universidade Federal de Santa Catarina. Atua ainda no Programa de Pós-Graduação Interdisciplinar em Ciências Humanas e no Mestrado Profissional de Ensino de História. Foi a coordenadora geral do Fazendo Gênero 11 e $13^{\circ}$ Women's Worlds Congress, realizado na UFSC em 2017. Tem experiência na área de História, com ênfase em História das Mulheres e do Gênero, atuando principalmente nos seguintes temas: gênero, memória, guerrilha, resistência às ditaduras no Cone Sul.

Luzinete Simões Minella (simoesluzinete@gmail.com) é doutora em Sociologia pela Universidad Nacional Autónoma de Mexico (UNAM, 1989), graduada (1972) e mestre (1977) em Ciências Sociais pela UFBA. Realizou estágio de Pós-Doutorado no Núcleo de Estudos de População da Universidade Estadual de Campinas (NEPO/Unicamp, 1998). Atualmente é Professora Adjunta IV aposentada da Universidade Federal de Santa Catarina (UFSC), atuando como professora voluntária no PPG Interdisciplinar em Ciências Humanas, onde coordena a área de Estudos de Gênero. Integra a equipe do Instituto de Estudos de Gênero (IEG), participando de vários dos seus projetos (eventos, publicações, cursos etc.). Publicou vários artigos em periódicos de ampla circulação, livros, trabalhos completos em anais de eventos etc. Assumiu a coordenação editorial da Revista Estudos Feministas entre 2001 e 2004 e entre 2007 e 2008, quando passou a integrar a editoria de artigos. Voltou a fazer parte desta coordenação em dezembro de 2016. É membro da Rede Iberoamericana de Ciencia, Tecnología y Género. Tem realizado pesquisas principalmente nas seguintes áreas: participação das mulheres nas ciências (na interface com a crítica feminista à ciência, aos estudos sociais da ciência e à história da ciência), gênero e saúde reprodutiva, gênero e infância, saúde mental. Orientou trabalhos de conclusão de curso e tem orientado dissertações e teses, principalmente nessas áreas.

Mara Coelho de Souza Lago (maralago07@gmail.com) é doutora em Psicologia da Educação pela Universidade Estadual de Campinas e Professora Emérita da Universidade Federal de Santa Catarina. Possui Graduação em Pedagogia pela Universidade do Estado de Santa Catarina (1967) e Mestrado em Antropologia Social pela Universidade Federal de Santa Catarina (1983). Atualmente é Professora Titular aposentada da Universidade Federal de Santa Catarina/ UFSC, atuando como docente voluntária no Programa de Pós-Graduação em Psicologia/PPGP e no Programa de Pós-Graduação Interdisciplinar em Ciências Humanas/PPGICH. Tem experiência na 
área de Psicologia, com ênfase em Psicologia Social, atuando principalmente nos temas gênero, gerações, subjetividades, modos de vida, com enfoque interdisciplinar. Participa do Instituto de Estudos de Gênero (IEG/UFSC) e da coordenação editorial da Revista Estudos Feministas.

Tânia Regina Oliveira Ramos (taniareginaoliveiraramos@gmail.com) é doutora em Literaturas de Língua Portuguesa pela Pontifícia Universidade Católica do Rio de Janeiro. Possui Graduação em Letras pela Universidade Federal de Santa Catarina, Mestrado e Doutorado em Literaturas de Língua Portuguesa pela Pontifícia Universidade Católica do Rio de Janeiro. Atualmente é Professora Titular e coordena o núcleo Literatura e Memória da UFSC, núcleo com projetos aprovados pela FAPESC e CNPq. Faz parte da Coordenação Geral da Revista Estudos Feministas e do Conselho Editorial das revistas Uniletras, Mafuá Ciências e Letras, Literatura Hoje, Signótica e Anuário de Literatura. É professora de Literatura Brasileira e Estudos Literários nos Cursos de Graduação e PósGraduação em Letras e Literatura na UFSC. Atua, pesquisa e publica nas linhas de pesquisa História e Memória, escritas de si e gênero.

\section{COMO CITAR ESSE ARTIGO DE ACORDO COM AS NORMAS DA REVISTA}

WOLFF, Cristina Scheibe; MINELLA, Luzinete Simões; LAGO, Mara Coelho de Souza; RAMOS, Tânia Regina Oliveira. "Pandemia na necroeconomia neoliberal". Revista Estudos Feministas, Florianópolis, v. 28, n. 2, e74311, 2020.

\section{CONTRIBUIÇÃO DE AUTORIA}

Elaboração e redação coletiva.

FINANCIAMENTO

Não se aplica.

CONSENTIMENTO DE USO DE IMAGEM

Não se aplica.

\section{APROVAÇÃO DE COMITÊ DE ÉTICA EM PESQUISA}

Não se aplica.

\section{CONFLITO DE INTERESSES}

Não se aplica.

LICENÇA DE USO

Este artigo está licenciado sob a Licença Creative Commons CC-BY Internacional. Com essa licença você pode compartilhar, adaptar, criar para qualquer fim, desde que atribua a autoria da obra.

\section{HISTÓRICO}

Recebido em 28/05/2020

Aprovado em 29/05/2020

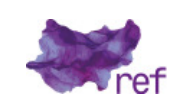

